\title{
Cell-Specific Kinetics and Efficiency of Herpes Simplex Virus Type 1 Entry Are Determined by Two Distinct Phases of Attachment
}

\author{
DEBORAH S. MCCLAIN AND A. OVETA FULLER ${ }^{1}$ \\ Department of Microbiology and Immunology, 6736 Medical Sciences II, University of Michigan Medical School. \\ Ann Arbor, Michigan 48109-0620
}

Received June 21, 1993: accepted September 27, 1993

\begin{abstract}
We previously provided evidence for a model of herpes simplex virus type 1 (HSV-1) entry by a cascade of interac. tions between components of the virion envelope and cellular plasma membrane (Fuller and Lee, 1992, J. Viro/. 66, 5002-5012). In this report we have determined entry kinetics of wild-type HSV-1 into two highly susceptible cell lines to further explore the contributions of viral or cellular factors to entry. Penetration rates of preattached virus varied among several common laboratory HSV-1 strains into one cell line. However, entry kinetics varied substantially for a single strain into highly susceptible HEp-2 or Vero cells under identical conditions. Plaquing efficiencies and sensitivity to heparin also significantly differed between these cells. Kinetics of entry that included virus attachment and penetration showed that the cell-specific effects can be explained by two distinct phases of attachment that occurred before penetration, but differed in duration on both susceptible cell lines. Initial attachment of virus is resistant to removal with phosphate-buffered saline, but sensitive to removal with buffer containing heparin. This is followed by a second type of attachment that is heparin resistant, but still sensitive to extracellular inactivation. We conclude that although undefined factors unique to individual wild-type HSV-1 laboratory strains affect entry kinetics, entry of any one strain is greatly influenced by interactions of virus with specific cell components during at least two distinct phases of attachment before penetration. Moreover, the second phase to stabilize binding seems to be the rate-limiting event in entry. Since major differences in the amounts or sulfation patterns of heparan sulfate were not detected, differences in the surfaces of HEp-2 and Vero cells that influence the kinetics and efficiency of HSV-1 entry are likely in the fine structure of heparan sulfate or in the presence and quantity of other unidentified receptors. (cs 1994 Academic Press, Inc.
\end{abstract}

Herpes simplex virus type 1 (HSV-1) can infect a broad range of cultured cells. Infectious entry occurs by direct fusion of the HSV-1 envelope with the cellular plasma membrane independent of low $\mathrm{pH}$ (Fuller and Spear, 1987: Wittels and Spear, 1990). Fusion for penetration and virion disassembly is likely triggered by virus envelope interactions with cell surface components during attachment. We proposed and provided evidence for a model of HSV-I entry through a cascade of multiple interactions between the virion envelope and cellular plasma membrane (Fuller and Lee, 1992). This entry model includes (a) initial attachment of the virion to heparan sulfate (HS) on cells, (b) subsequent stable attachment that primes virion-cell fusion, (c) initiation of a fusion pore formed between the virus envelope and plasma membrane, (d) expansion of the fusion bridge and disassembly of virion structure, and (e) release of the nucleocapsid into the cell cytoplasm. In this report, we further explore HSV-1 interactions with cells during neutral $\mathrm{pH}$ entry.

Studies of the role of individual viral or cellular components suggest that HSV-1 entry is complex and involves many envelope glycoproteins and one or more

\footnotetext{
1 To whom correspondence and reprint requests should be addressed.
}

cell surface components (Spear, 1993). Of $10 \mathrm{ge}$ nome-encoded glycoproteins, the presence of $\mathrm{gC}$ enhances infectivity (Herold et al., 1991), and gB, gD, and $\mathrm{gH}$ are essential for events subsequent to attachment (Cai et al., 1988; Desai et al., 1988; Forrester et al., 1992; Fuller et al., 1989; Fuller and Spear, 1987; Ligas and Johnson, 1988). gC, gB, and gD have been shown to bind independently to cells (Kuhn et al., 1990), and at least $\mathrm{gC}$ and $\mathrm{gB}$ bind to $\mathrm{HS}$ on the cell surface (Hérold et al., 1991). HS is a sulfated glycosaminoglycan (GAG), attached to cellular proteoglycans, that is ubiquitously distributed on a broad range of cells (Kjellén and Lindahl, 1991; Wight et al., 1991). HSV-1 infectivity is reduced by removal or alteration of cell surface heparan sulfate or by the presence of heparin, a chemically similar GAG (Gruenheid et al., 1993; Nahmias and Kibrick, 1964; Shieh et al., 1992; WuDumn and Spear, 1989). HS is currently the sole identified cell surface component with which HSV-1 interacts. Other HSV-1 cellular receptors have been postulated, but their identity and role in entry have not yet been determined (Campadelli-Fiume et al., 1988; Fuller and Lee, 1992; Johnson et al., 1990; Johnson and Ligas, 1988; Johnson and Spear, 1989; Lee and Fuller, 1993; Subramanian et al., 1994). gD does not mediate fusion but binds to a saturable non-HS receptor to mediate stable at- 
tachment that resists heparin elution (Fuller et al., 1994; Fuller and Lee, 1992; Johnson and Ligas, 1988; Lee and Fuller, 1993). $\mathrm{gH}$ is required for entry (Desai et al., 1988; Forrester et al., 1992; Fuller et al., 1989), may bind a non-HS cellular component (Forrester et al., 1992; Lee and Fuller, 1993), and is one of the viral glycoproteins involved in initiation of membrane fusion (Fuller et al., 1994; Fuller and Lee, 1992).

The multiple viral envelope and cell surface components implicated in HSV infection present a challenge to understanding its entry into susceptible cells. Critical viral glycoproteins may directly interact with cell surface components or may facilitate the function of another viral glycoprotein or component. The classical approach of characterizing virus or cell mutants provides valuable insights. However, if the functions of glycoproteins are interdependent, viral mutants lacking a glycoprotein or with multiple lesions may provide limited information about the entire entry process. Understanding how HS or other cellular factors may contribute to HSV-1 attachment also has not been straightforward. Viral attachment to HS may be useful, or essential, for initial attachment and also for subsequent events that lead to virus penetration. Results obtained with Chinese hamster ovary $(\mathrm{CHO})$ cell lines that are defective in HS or proteoglycans (Shieh et al., 1992) are complicated by the natural resistance of $\mathrm{CHO}$ cells to HSV-1 infection (Huang et al., 1974). Wild-type $\mathrm{CHO}$ cells required 10 -fold more input virus than highly susceptible HEp-2 cells to synthesize comparable levels of early viral proteins (Shieh et al., 1992). This result suggests that factors other than HS chains, such as different core proteins and the presence of other GAGs (Wight et al., 1991) or of other cell factors may affect HSV-1 entry or uncoating. Because the biogenesis of HS-bearing proteoglycans is complex and incompletely understood (Kjellén and Lindahl, 1991; Wight et al., 1991), producing mutants in HS may result in multiple lesions and partially susceptible phenotypes, as found in groC L cell mutants (Gruenheid et al., 1993). Varied approaches are required to understand the overall interdependent cascade of interactions that facilitate HSV-1 entry.

In this report, we examined virus-cell interactions by determining the kinetics of HSV-1 entry as an entire cooperative process without introducing known changes from spontaneous or engineered mutations of either virus or cell components. We find that HSV-1 attaches in at least two distinct phases prior to virus penetration. Not surprisingly, and likely due to natural variation or accumulated variations from in vitro culture, common wild-type laboratory virus strains penetrated at different rates into a single cell line. Moreover, a single strain of wild-type HSV-1 attached and penetrated at different rates into two susceptible cell lines, HEp-2 and Vero. The cell-specific differences ob- served in HSV penetration kinetics and plaquing efficiencies can be explained by differences in the type and duration of virus attachment. We find that $\mathrm{HS}$ is very similar on HEp-2 and Vero cells. Thus, the fine structure of HS or the presence of non-HS receptors likely accounts for cell-specific attachment and entry kinetics.

\section{MATERIALS AND METHODS}

\section{Cells and viruses}

Human epithelial carcinoma (HEp-2) and African green monkey kidney (Vero) cell lines were obtained from ATCC and maintained as described previously (Fuller and Lee, 1992). We routinely cultured all virus strains at $34^{\circ}$ on HEp-2 cells using a standard low virus input, $0.01 \mathrm{PFU} / \mathrm{cell}$, of virus stocks not more than two passages from mother pool stocks. However, previous history of virus cultivation cannot be clearly documented. HSV-1 strains used were common wild-type laboratory strains F, 17 syn+, HFEM, and KOS. These viruses do not fuse cultured cells and have no known large alterations in virus structure. A stock of HSV1 (KOS) known to be close to the original isolate, designated as $K O S(b)$ in this report for convenience, was kindly provided by P. Schaffer. HSV-1(17 syn+) was kindly provided by Jeffrey Engel (Goodman and Engel, 1991). Infectious titers of all virus stocks were greater than $1 \times 10^{9} \mathrm{PFU} / \mathrm{ml}$.

\section{Assay of rate of penetration}

For one set of kinetic studies (Fig. 1), we used a slight modification of the classical rate of penetration assay to examine binding and entry that leads to virus infectivity (Herold et al., 1991; Highlander et al., 1988; Huang and Wagner, 1964). HEp-2 or Vero monolayers at approximately $80 \%$ confluency in six-well dishes were paired, so that each pair of wells represented one of successive time points. Cell monolayers were incubated for $2 \mathrm{~min}$ on ice and then infected with 200-300 PFU/monolayer of the designated virus. Virus was adsorbed to cells at $4^{\circ}$ for $90 \mathrm{~min}$, inoculum removed, and monolayers washed three times with PBS at $4^{\circ}$ before incubation with medium prewarmed to $37^{\circ}$. At time points beginning immediately after the temperature shift, progress of virus penetration was determined from the amount of virus resistant to inactivation by low $\mathrm{pH}$ citrate buffer wash (Huang and Wagner, 1964). After removal of medium from a pair of wells, monolayers were washed twice with PBS. Each of two wells was incubated with either PBS (control) or citrate buffer at $\mathrm{pH} 3.0$ for 2 min before washing twice with PBS (Huang and Wagner, 1964). HEp-2 monolayers were overlaid with Dulbecco's modified medium (DME) containing $5 \%$ calf serum (Hyclone), and Vero cells 
with medium 199 containing $5 \%$ calf serum. Each medium also contained $50 \mathrm{mM}$ HEPES, at $\mathrm{pH} 7.4$, and $0.5 \%$ methylcellulose. At $72 \mathrm{hr}, \mathrm{HEp}-2$ monolayers were fixed with $1 \%$ glutaraidehyde and plaques immunostained with a polyclonal antibody specific for the secreted form of HSV gD (Fuller and Spear, 1985). Secondary antibody was biotinylated goat anti-rabbit immunoglobulin (Gibco-BRL). The indicator reagent, streptavidin $\beta$-galactosidase conjugate, was developed with the substrate Bluogal (Gibco-BRL). Plaques on Vero cells were either immunostained or fixed with methanol and stained with Giemsa.

In an exception to this procedure, rates of penetration were simultaneously determined for virus exposed to HEp-2 cells at (1) $37^{\circ}$ without prior adsorption, (2) $4^{\circ}$ without prior adsorption, and (3) $4^{\circ}$ for $90 \mathrm{~min}$, and then shifted to $37^{\circ}$ (Fig. 1).

\section{Assay of rate of attachment}

Rate of attachment was measured as time required for virus to attach to cells to resist removal by wash with PBS or heparin, and time required to be protected from extracellular inactivation. Time points began immediately upon exposure of virus to cells. Virus was not preattached to cells nor was there a temperature shift during attachment. Sets of three cell monolayers at $80 \%$ confluency were infected with $300-400$ PFU of $\mathrm{HSV}-1$ (F) per monolayer at either $37^{\circ}$ or $4^{\circ}$. Input infectivity was calculated from titers of HSV-1(F) on HEp-2 cells. For the first time point, immediately after infection, the inoculum was removed from one set of three monolayers and the monolayers were washed twice with PBS. One well was treated with PBS, one with PBS containing $500 \mu \mathrm{g} / \mathrm{ml}$ heparin (Sigma), and one with citrate buffer at $\mathrm{pH} 3.0$ as described for the rate of penetration. Heparin concentrations were chosen from a dose-response curve (Fig. 2) and provided conditions similar to those used to select heparin-resistant mutants (Goodman and Engel, 1991). Subsequently, all monolayers were overlaid with medium, incubated, fixed, and stained, and the plaques were scored.

\section{Heparin resistance assay}

HSV-1(F) was diluted to approximately $4000 \mathrm{PFU} / \mathrm{ml}$ and preincubated with heparin at the indicated concentrations for $15 \mathrm{~min}$ at room temperature. HEp-2 or Vero cells in duplicate received the same inocula for 90 min at $37^{\circ}$. To ensure a countable number of plaques, virus incubated with less than $0.1 \mu \mathrm{g} / \mathrm{ml}$ heparin was diluted 10 -fold into the same concentrations of heparin used prior to infecting cells. Infected monolayers were washed twice with either DME or 199 media containing $5 \%$ calf serum and $0.2 \%$ human immunoglobulin, overlaid with this medium, and incubated at $37^{\circ}$ until plaques were evident. Cells were fixed and immuno- stained and plaques scored as described in the rate of penetration assay. Heparin resistance of HSV-1 strains HFEM, KOS(a), KOS(b), and 17 syn+ were similarly assayed with, or without, heparin at $10 \mu \mathrm{g} / \mathrm{ml}$ on HEp-2 cells and at $300 \mu \mathrm{g} / \mathrm{ml}$ on Vero cells based on the heparin dose curve (Fig. 2).

\section{Purification of heparan sulfate proteoglycans}

$\left[{ }^{3} \mathrm{H}\right]$ glucosamine and $\left[{ }^{35} \mathrm{~S}\right]$ sulfate were purchased from Amersham Corp.; Q-Sepharose Fast Flow, prepacked Superose $6(1 \times 30 \mathrm{~cm})$ and Sephadex G-50 (fine) were from Pharmacia LKB Biotechnology Inc.; Guanidine $\mathrm{HCl}$, urea, and phenylmethylsulfonyl fluoride were from Life Technologies/Bethesda Research Laboratories; Triton X-100 was from Pierce Chemical Co.; the detergent CHAPS was from Calbiochem; chondroitin sulfate $\mathrm{ABC}$ lyase (Proteus vulgaris) and heparitinase (Flavobacterium heparinum) were from Seikagaku America; 6-aminohexanoic acid, benzamidine $\mathrm{HCl}$, and $\mathrm{N}$-ethylmalemide were from Sigma; and barium nitrite was from Fulka $A G$.

To label cell GAGs, approximately $3 \times 10^{6} \mathrm{HEp}-2$ or Vero cells were plated in $25-\mathrm{cm}^{2}$ flasks in a final volume of $5 \mathrm{ml}$ DME with $8 \%$ fetal bovine serum. Radioisotopes $\left[{ }^{35} \mathrm{~S}\right]$ sulfate and $\left[{ }^{3} \mathrm{H}\right]$ glucosamine were added at $50 \mu \mathrm{Ci} / \mathrm{ml}$ each at the time of plating and cultures incubated at $37^{\circ}$ for $24 \mathrm{hr}$. To purify radiolabeled HSPG, guanidine $\mathrm{HCl}$ extracts of cell monolayers and media were analyzed by Sephadex G-50 column chromatography $\langle 8-\mathrm{m}$ bed volume equilibrated with $8 \mathrm{M}$ urea, 0.3 $M$ sodium chloride, $50 \mathrm{~m} M$ sodium acetate, $\mathrm{pH} 6.0$, containing $0.5 \%$ CHAPS) and the radiolabeled macromolecules were isolated and quantified by scintillation spectroscopy (Yanagishita et al., 1987). Isolated macromolecules were analyzed by $\mathrm{Q}$-Sepharose anion-exchange chromatography. Samples were applied to 2$\mathrm{ml}$ columns $(0.7 \times 5 \mathrm{~cm})$ and eluted with a $40-\mathrm{ml}$ linear gradient of sodium chloride $(0.3-1.2 \mathrm{M})$ in $8 \mathrm{M}$ urea, $0.5 \%$ CHAPS, $50 \mathrm{mM}$ sodium acetate, $\mathrm{pH} 6.0$ (Yanagishita et al., 1987). One-milliliter fractions were collected and monitored for radioactivity and conductivity. Proteoglycan fractions from Q-Sepharose chromatography were identified by their ${ }^{35} \mathrm{~S}$ radioactivity profile. Pooled samples of proteoglycans were digested with chondroitin sulfate $\mathrm{ABC}$ lyase $(100 \mathrm{mlU} / \mathrm{ml})$ in $0.1 \mathrm{M}$ Tris, $0.1 \mathrm{M}$ acetate, $\mathrm{pH} 7.3$, for $60 \mathrm{~min}$ at $37^{\circ}$ (Yanagishita, 1992). Digested proteoglycans were analyzed by Q-Sepharose anion-exchange chromatography. Fractions containing ${ }^{35} \mathrm{~S}$ radioactivity were pooled, dialyzed against $\mathrm{H}_{2} \mathrm{O}$, and lyophilized.

\section{Characterization of HSPG}

HSPG pools for cell fractions were reconstituted in $\mathrm{H}_{2} \mathrm{O}$ and vacuum dried. GAGs were prepared by treating labeled HSPG with alkaline borohydride in $1-\mathrm{m} / \mathrm{vol}$ 
of $0.05 \mathrm{M}$ sodium hydroxide, $1.0 \mathrm{M}$ sodium borohydride at $45^{\circ}$ for $24 \mathrm{hr}$. Excess borohydride was destroyed by neutralizing the solution with $5.0 \mathrm{M}$ acetic acid. GAGs were differentially cleaved by either heparitinase digestion or nitrous acid treatment. Heparitinase digests were performed identically to chondroitin sulfate $A B C$ lyase digests, except that $5 \mathrm{mUU} / \mathrm{ml}$ of enzyme was used. Nitrous acid treatment was performed at low pH (Shively and Conrad, 1976). Following treatment, the volumes of the samples were reduced to 250 $\mu \mathrm{l}$. An equal volume of $8 \mathrm{M}$ guanidine $\mathrm{HCl}$ was added to bring the final concentration of the treated samples to $4 \mathrm{M}$ guanidine $\mathrm{HCl}$. Alkaline borohydride-treated samples were analyzed by chromatography on Superose 6 columns, and both heparitinase- and nitrous-acidtreated samples were analyzed by chromatography on Superdex 75 columns. Columns were equilibrated and eluted in $4 \mathrm{M}$ guanidine $\mathrm{HCl}, 50 \mathrm{mM}$ sodium acetate, $0.5 \%$ Triton $\mathrm{X}-100, \mathrm{pH} 6.0$, at a flow rate of $0.4 \mathrm{ml}$.

The average molecular weights of HS chains were calculated from the Superose 6 chromatography profiles, using the formula $M W=e^{[3.150-k d / 0.253]}$. The percentages of $\mathrm{N}$-sulfated glucosamine residues (GlcN) were calculated by comparing the radioactivity present in populations of nitrous acid fragments separated by Superdex 75 chromatography. Proportions of $\mathrm{N}$-sulfated glucosamine (GlcN) residues in nitrous acid fragments are $1 / n$, where $n$ represents the number of GlcN-anhydromannose residues in the fragment $(n=1$ for disaccharides, $n=2$ for tetrasaccharides, etc). If $p_{n}$ is the proportion of fragments with $n$ residues compared to all fragments, then the proportion of GLcN residues containing $N$-sulfate in the original heparan sulfate is $\left(1 / n \times p_{n}\right)$.

\section{RESULTS}

\section{Characteristics of $\mathrm{HSV}-1$ rate of penetration assay}

In one approach to determine the influence of virus or cellular components on HSV-1 entry and infectivity, we examined entry with a classical rate of penetration assay (Huang and Wagner, 1964). Rate of penetration denotes the time required for virus to penetrate into cells, thus escaping extracellular inactivation by low $\mathrm{pH}$ buffer. This inactivation presumably results from irreversibly altered conformation of virus components. Virus attaches to cells during incubation at $4^{\circ}$, but only penetrates when the temperature is increased (Huang and Wagner, 1964). Increase in infectivity, quantitated as increasing numbers of plaques over time, represents progression of preattached virus through penetration. We determined in our system if this assay was appropriate for examining kinetics of HSV-1 interactions with cells.

Greater than $95 \%$ of $\mathrm{HSV}-1$ (F) virus that attached to $\mathrm{HEP}-2$ cells during 90 min at $4^{\circ}$ was inactivated when cells were treated with low $\mathrm{pH}$ buffer at $4^{\circ}$ and subsequently shifted to $37^{\circ}$ to allow penetration of surviving virus (Fig. 1A, open squares). Consistent with the original observation (Huang and Wagner, 1964), and with generally assumed characteristics of HSV entry, at $4^{\circ}$ in our system (1) virus attached, (2) virus did not penetrate, and (3) the low $\mathrm{pH}$ buffer efficiently inactivated bound extracellular virus. If virions were exposed to low $\mathrm{pH}$ buffer after both incubation for 90 min at $4^{\circ}$ and temperature shift to $37^{\circ}, 50 \%$ of the preattached infectious virions were protected in $7 \mathrm{~min}$ (Fig. 1A, open circles). In contrast, for virus incubated with cells at $37^{\circ}$ without preattachment, $50 \%$ protection required $20 \mathrm{~min}$ (Fig. 1A, solid circles). These results show that protection from extracellular inactivation isolates entry and delineates the rate of penetration of a virus population. They clearly document and extend several generally accepted characteristics of HSV-1 entry. First, the temperature of initial virus interaction with cell surfaces during infection affects the efficiency of virus attachment both in time required and in overall numbers (Fig $1 \mathrm{~A}$ and Table 1). Second, consistent with a proposed function of attachment to prime fusion for penetration (Fuller and Lee, 1992), attachment that occurs at $4^{\circ}$ arrested the virus population at a stage primed for immediate penetration when the temperature is raised (Fig. 1A). We used this classical penetration assay, or a variation thereof, to examine the influence of interactions between viral and cell surface factors on kinetics of HSV-1 entry into highly susceptible cells.

\section{Influence of cell type and strain variation on penetration rate}

If HSV enters through a cascade of interdependent events, binding of viral components to unique cell surface components likely affects entry rate and efficiency of infection. Variation in the envelope composition of individual HSV-1 strains also might influence cooperativity required for entry. We determined the kinetics of penetration of HSV-1(F) into HEp-2 and Vero cells and of several common wild-type laboratory HSV-1 strains into HEp-2 cells (Figs. $1 \mathrm{~B}$ and $1 \mathrm{C}$ ). Preattached HSV$1(F)$ penetrated more quickly into HEp-2 cells than Vero cells (Fig. 1B). Fifty percent of the viral population was protected by 7 min on HEp-2 cells compared to over twice as long (16 min) on Vero cells. The results indicated cell-specific differences in penetration of one virus strain.

To determine whether the penetration rate of HSV$1(F)$ was representative of other strains, penetration rates of several randomly chosen common wild-type laboratory HSV-1 strains were compared on HEp-2 cells. None of these viruses are known to carry extensive mutations that affect entry. The penetration rates of wild-type strains $F$ and 17 synt were similar $\left\langle t_{50}=7\right.$ 

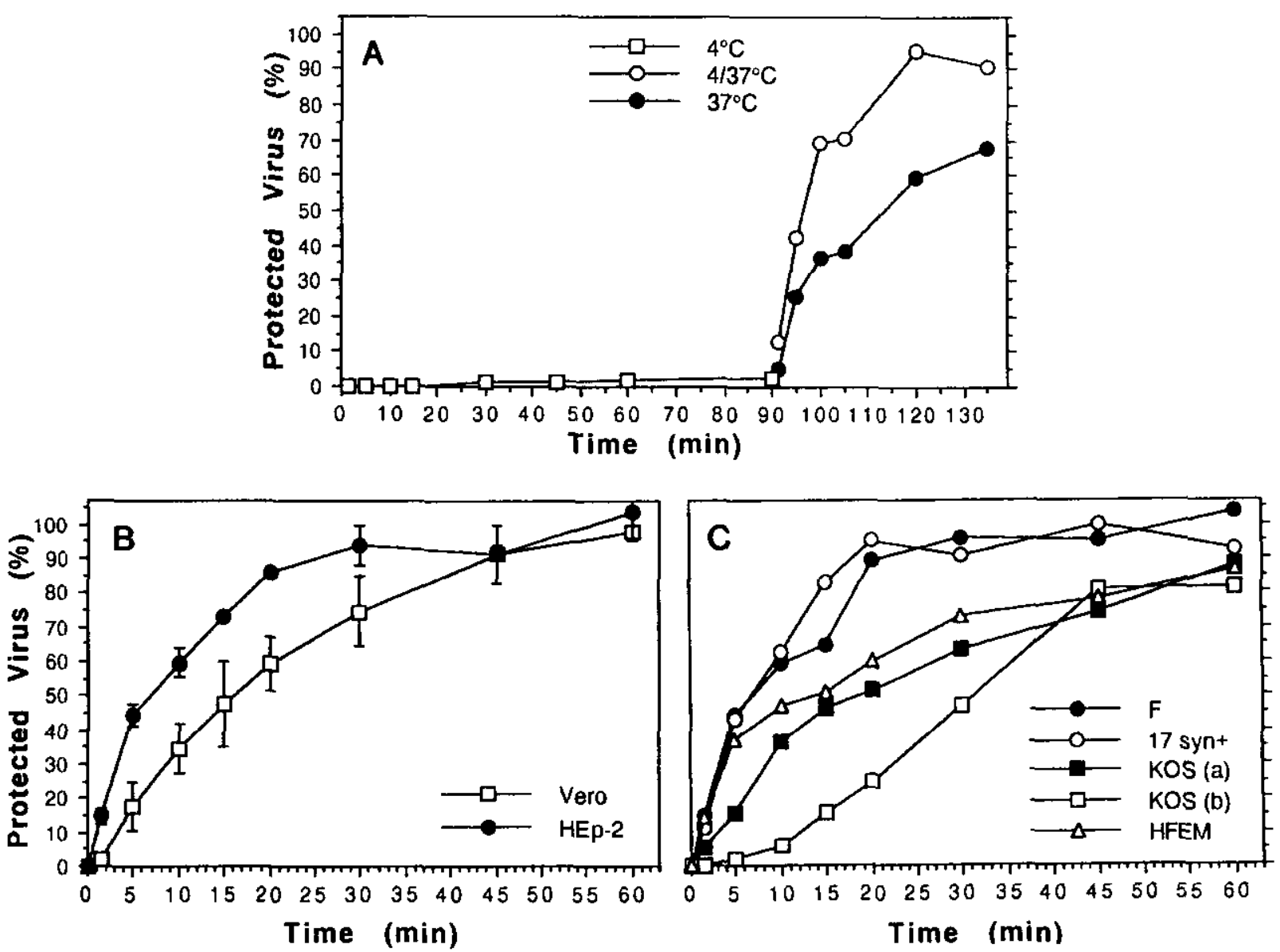

Fig. 1. Rates of HSV-1 penetration. (A) The effect of temperature and preattachment of HSV-1 on the rate of penetration. HEp-2 monolayers in six-well dishes were inoculated with 300 PFU of HSV-1(F) at $37^{\circ}$ or $4^{\circ}$. Immediately after inoculation at $37^{\circ}$ (solid circles), at $4^{\circ}$ (open squares), or after 90 -min incubation at $4^{\circ}$ followed by a shitt to $37^{\circ}$ (open circles), the inoculum was removed and the cells were washed three times with PBS. Duplicate cell monolayers were treated for $2 \mathrm{~min}$ with low pH citrate buffer or with PBS (control), then washed twice with PBS, and overlaid with DME containing $0.5 \%$ methyicellulose. Cell monolayers were fixed and plaques immunostained at $72 \mathrm{hr}$. The number of infectious virus surviving low $\mathrm{pH}$ inactivation by citrate treatment at each time point is expressed as a percentage of the virus from wash at each time point. (B and $\mathrm{C}$ ) The rates of penetration into Vero and HEp-2 cells or among HSV-1 strains. For $\mathrm{B}, \mathrm{HEp}-2$ and Vero monolayers were inoculated with 300 PFU of HSV-1 (F). For C, HEp-2 monolayers were similarly inoculated with HSV-1 strains 17 syn+ (open circles), KOS(a), KOS(b), or HFEM. After incubation at $4^{\circ}$ for $90 \mathrm{~min}$ the monolayers were washed, shifted to $37^{\circ}$, and treated as described for $\mathrm{A}$. The percentage of infectious virus surviving low $\mathrm{pH}$ citrate inactivation is compared to the PBS control value at each time point. Each point is the average of at least triplicate determinations. Standard deviations (less than 15\%) were omitted in C for legibility.

min), while those of both $\operatorname{HFEM}\left(t_{50}=10 \mathrm{~min}\right)$ and two preparations of $\operatorname{KOS}\left(t_{50}=15\right.$ and $30 \mathrm{~min}$ ) varied from the rates of $F$ and 17 syn+ and varied among themselves (Fig. 1C). These results indicate that the kinetics of penetration of common wild-type HSV-1 laboratory strains differ substantially under identical conditions on the same cell line. The penetration rate of HSV-1(F) was similar to that of strains with similar characteristics of stability and plaque morphology. Minor natural variations in HSV-1 strains, or possible accumulated variations from in vitro propagation, which are difficult to systematically evaluate, may contribute to subtle virus strain differences that affect kinetics of penetration into a given cell line.

Although common wild-type laboratory HSV-1 strains enter HEp-2 cells at different rates (Fig. 1C), there were significant differences between the penetration rates of a single strain, HSV-1(F), into HEp-2 and Vero cells under identical incubation conditions (Fig. $1 \mathrm{~B})$. This suggested that virus interaction with unique cell factors greatly influences the events required to mediate infectious entry. We further explored the cellspecific interactions of HSV-1(F) with HEp-2 and Vero cells.

\section{Plaquing efficiency of HSV-1}

HEp-2 and Vero cells are frequently used for culture and study of HSV-1. It has been widely observed that plaque morphologies and the efficiency of plaque formation of many laboratory strains differ on these two susceptible cell lines. Table 1 confirms that HSV-1 
TABLE 1

Efficiency of HSV-1 Plaque Formation ${ }^{B}$

\begin{tabular}{ccc}
\hline & \multicolumn{2}{c}{ Temperature } \\
\cline { 2 - 3 } Cell & $4^{\circ}$ & $37^{\circ}$ \\
\hline HEp-2 & 78 & $187(42 \%)^{\circ}$ \\
Vero & 192 & $222(86 \%)$ \\
& $(41 \%)^{c}$ & $(84 \%)$ \\
\hline
\end{tabular}

${ }^{a}$ Number of plaques resulting from 90-min incubation of HSV-1(F) on indicated cell line at indicated temperature.

${ }^{\circ}$ Percentage of infectious virions seen at $4^{\circ}$ compared to that seen at $37^{\circ}$.

c Percentage of infectious virions seen as plaques on HEp-2 compared to that seen on Vero.

forms more plaques on Vero cells than HEp-2 cells exposed simultaneously to the same virus inoculum. The temperature at which virions interact with cells also influences plaquing efficiency. HEp-2 cells are more sensitive to temperature for attachment than Vero cells (Table 1). An important contributing factor to these differences might be interactions among virus and cell surface components during the cascade of entry events. The cell-specific plaquing efficiencies did not correlate with cell-specific HSV-1 penetration rates (Fig. 1B and Table 1), since faster penetration of HSV$1(F)$ into HEp-2 celis does not seem to directly result in formation of more plaques.

\section{Correlation of virus penetration rates with sensitivity to heparin}

Differences in attachment to HS might influence penetration rate, since binding to $\mathrm{HS}$ is important to HSV-1 entry (Herold et al., 1991; Shieh et al., 1992; WuOunn and Spear, 1989). We determined if penetration rate correlated with the ability of HSV-1 to bind to $\mathrm{HS}$, as measured by sensitivity to heparin competition. This approach assumes that HSV-1 binding to heparin mimics binding to cell surface HS (Goodman and Engel, 1991; WuDunn and Spear, 1989). We assayed infectivity because only virions that attach to $\mathrm{HS}$, or another cell component, in preference to heparin could form plaques. Consistent cell-specific differences also were evident in a dose-response of the effect of heparin on HSV-1(F) infectivity (Fig. 2). On HEp-2 cells, virus infectivity was reduced to less than $1 \%$ at $1 \mu \mathrm{g} / \mathrm{ml}$ of heparin. In contrast, approximately $10 \%$ of input virus could infect Vero cells even in the presence of up to $500 \mu \mathrm{g} / \mathrm{ml}$ of heparin.

Relative sensitivity to heparin of wild-type laboratory HSV-1 strains was examined on both cell lines. Cellspecific differences consistently were more pronounced than differences among the wild-type strains (Fig. 3). All of the virus strains were reduced to less than $1 \%$ infectivity on HEp-2 cells with $10 \mu \mathrm{g} / \mathrm{ml}$ heparin (Fig. 3). The same strains retained a range of $2-10 \%$ infectivity on Vero cells even in the presence of 300 $\mu \mathrm{g} / \mathrm{ml}$ of heparin. The infectivity of each strain in the presence of heparin was greatly influenced by cell type and did not obviously correlate with penetration rate (Figs. 1, 2, and 3). In heparin sensitivity, the cell-specific differences are greater than discernible variations among common wild-type virus laboratory strains.

\section{Kinetics of attachment and penetration of HSV-1 strains}

Penetration rate, plaquing efficiency, and heparin sensitivity consistently show a major influence of cellspecific factors on HSV-1 entry (Table 1, Figs. 1, 2, and 3). We more closely examined the kinetics of entry of one strain, HSV-1(F), into HEp-2 and Vero cells by modifying the classical rate of penetration assay. Since this assay examines entry of virus preattached at $4^{\circ}$ (Fig. iA), the penetration rates do not represent virus-cell



FIG. 2. Effects of heparin on HSV infectivity on HEp-2 and Vero cells. HSV-1(F) viral stock was diluted to approximately 4000 PFU/ $\mathrm{ml}$, then duplicate aliquots were treated with or without the indicated concentrations of heparin. Confluent monolayers of either HEp-2 (solid circles) or Vero cells (open squares) were incubated with the virus inocula for $90 \mathrm{~min}$ at $37^{\circ}$. The cell monolayers were washed twice with medium containing human gamma globulin, in DME on HEp-2 cells or 199 on Vero cells, and overlaid with the same media. Plaques were scored when clearly visible. The PFU formed in the presence of heparin is presented as the average number of resistant virus $(A)$ and the percentage of resistant virus compared to PFU in the absence of heparin (B). Standard deviations were consistently less than $10 \%$ 




FIG. 3. Heparin resistance of wild-type HSV-1 strains on HEp-2 and Vero cells. Stocks of HSV-1 strains were diluted and duplicate aliquots were treated with or without $10 \mu \mathrm{g} / \mathrm{ml}$ heparin (HEp-2 cells) or $300 \mu \mathrm{g} / \mathrm{ml}$ heparin (Vero cells). Confluent monolayers of either HEp-2 or Vero cells were incubated with virus and treated as in the legend to Fig. 2. The PFU formed in the presence of heparin is presented as the percentage of PFU formed in the absence of heparin on Vero cells (hatched bars) or on HEp-2 cells (solid bars). Fewer than $1 \%$ of virus from parallel inoculations formed plaques on $\mathrm{HEp}-2$ cells. The experiment was performed in triplicate for each virus on each cell line. Error bars indicate standard deviations.

interactions throughout the entire entry process. For instance, virus preattached at $4^{\circ}$ penetrated faster than virus that had not undergone the $4^{\circ}$ incubation (Fig. 1A). Moreover, by 90 min postinfection at $4^{\circ}$, approximately $80 \%$ of input virions were attached to resist removal by heparin wash (data not shown). Cellspecific differences that influence entry and infection could be obscured by the $4^{\circ}$ virus preattachment (Herold et al., 1991; Highlander et al., 1988; Huang and Wagner, 1964).

To evaluate the influence of attachment on entry, virus attachment through penetration was examined at either $37^{\circ}$ or $4^{\circ}$ after exposure of the cells to one of three conditions (Fig. 4). These were wash with PBS to remove unattached virus, wash with PBS containing $500 \mu \mathrm{g} / \mathrm{ml}$ of heparin to remove virus not stably attached to cells, or extracellular inactivation by low $\mathrm{pH}$ citrate buffer to identify virus that had penetrated successfully through the cell membrane. When entry events are isolated and assessed by plaque formation in parallel on HEp-2 and Vero cells, kinetics of HSV-1(F) entry showed that infectious virus enters in at least three phases that can be discerned by different wash conditions (Fig. 4). These phases are evident when the number of infectious particles that are resistant to a given condition at a given time is determined. Moreover, efficiency of entry and the time virus spend in transition through these phases are influenced by temperature and cell type and can provide an explanation for cell-specific observations. Table 2 shows the time required for $50 \%$ of the infectious virus population to reach each phase.
Kinetics of entry that include virus attachment explain the influence of temperature and cell-specific differences observed in HSV-1 $F\rangle$ plaquing efficiency, penetration rate, and possibly heparin sensitivity (Table 1, Figs. 2 and 3). With plaquing efficiency, for example, at either temperature and regardless of wash condition (PBS wash, open squares; heparin wash, open circles; or citrate inactivation, solid triangles at $37^{\circ}$ only), almost twice as many virions attached to Vero cells in 20 min (Figs. 4B and 4D) than attached to HEp-2 cells (Figs. $4 \mathrm{~A}$ and $4 \mathrm{C}$ ). During the 90-min incubation in a standard plaque assay, greater numbers of virions likely attach to Vero cells than to HEp-2 cells. Over a set time, more of these virions eventually enter Vero cells to form plaques (Table 1). Kinetics of entry to include attachment also agree with observed effects of temperature. For example, the transition from PBS(R) but $\mathrm{Hep}(\mathrm{S})$ (open squares) to virus that was both PBS(R) and $H e p(R)$ (open circles) differs on HEp-2 and Vero cells and occurs at both $37^{\circ}$ and $4^{\circ}$ (Fig. 4). However, transition from Hep(R) virus to virus protected from extracellular inactivation, Cit $(R)$ (solid triangles), occurs only at $37^{\circ}$, possibly because events leading to or during penetration are inhibited at $4^{\circ}$.

Cell-specific penetration rates of preattached HSV1 (F) (Fig. 1B) also are consistent with, and can be explained by, the three discernible, interdependent phases of entry (Fig. 4, Table 2). On HEp-2 cells, HSV$1(\mathrm{~F})$ spends twice as long ( $32 \%$ of total time) in transition from $P B S(R)$ to $H e p(R)$ than it does in transition from $\mathrm{Hep}(\mathrm{R})$ to $\mathrm{Cit}(\mathrm{R})$ (14\% of total time). Surprisingly, this trend is reversed on Vero cells (Fig. $4 \mathrm{~B}$ and Table 2), where transition from $P B S(R)$ to $H e p(R)$ occurs quickly ( $11 \%$ of total time) relative to the longer time required (32\% of total time) for transition from $\mathrm{Hep}(\mathrm{R})$ to $\mathrm{Cit}(\mathrm{R})$. Consistent with measure of the classical rate of penetration (Fig. 1B), preattached $\mathrm{Hep}$ (R) virus take relatively longer to penetrate into Vero cells than HEp-2 cells (Table 2, Fig. 4). However, because more virions reach the Hep $(R)$ phase in less time on Vero cells (Table 2, Fig. 4), more plaques are formed. Therefore, the slower penetration rate on Vero cells does not result in decreased plaquing efficiency (Table 1).

Heparin sensitivity on HEp-2 and Vero cells (Figs. 2 and 3 ) also correlates with kinetics of attachment at $37^{\circ}$ (Fig. 4). Virions attach quickly $(50 \%$ in less than 10 min) in both PBS(R) and Hep(R) manners to Vero cells (Fig. 4B and Table 2), perhaps propelling the entry process past the heparan sulfate binding phase of viruscell interaction that is subject to heparin competition. Thus, for Vero cells, more virions may be resistant to heparin since the second phase of attachment, or penetration, begins sooner on Vero cells. The longer time to reach Hep(R) on HEp-2 cells (27 min) (Fig. 4A, Table 2) indicates that virus may be more susceptible to the 

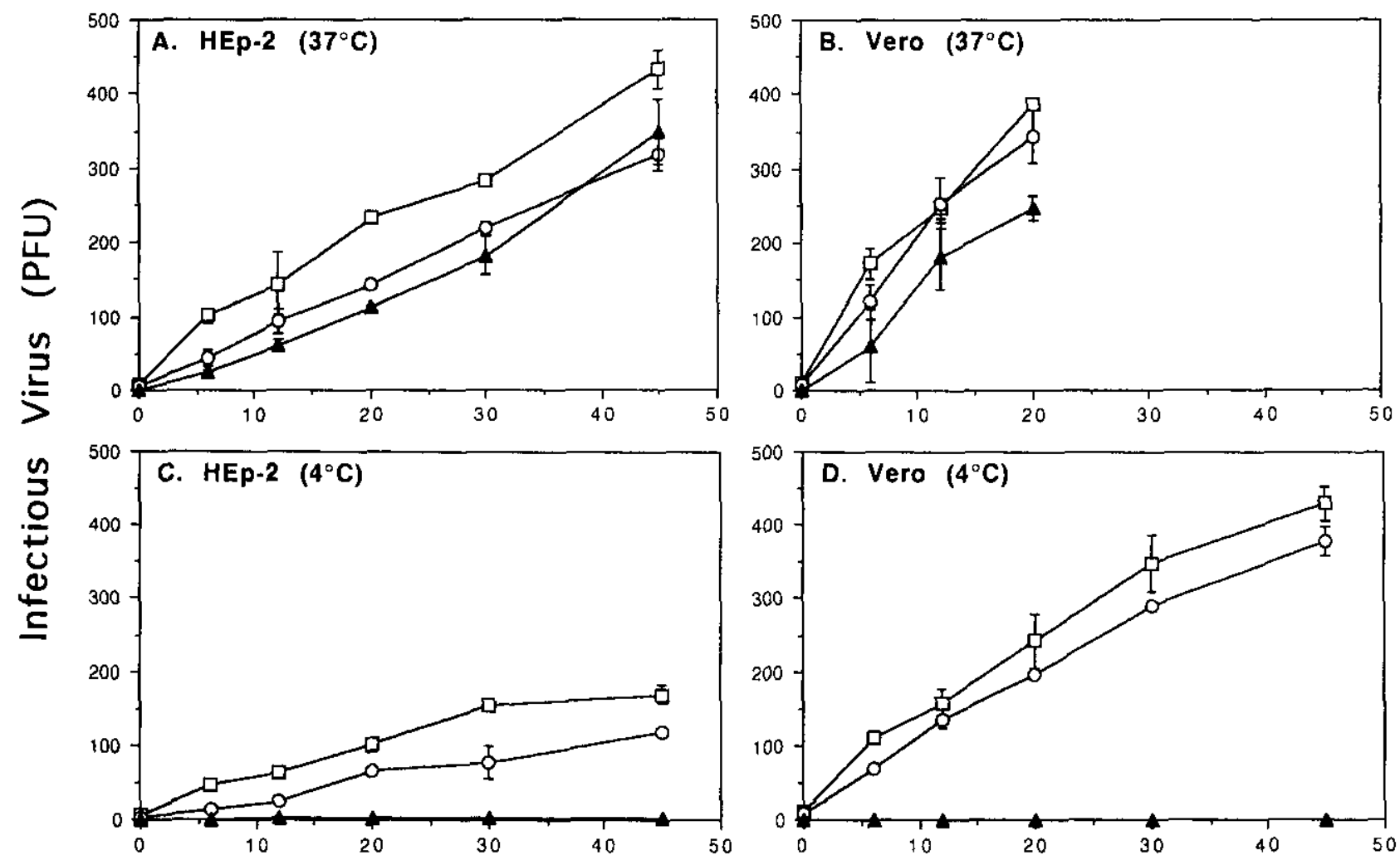

Time $(\mathrm{min})$

FiG. 4. Rates of attachment and penetration of HSV-1(F) on HEp-2 or Vero cells at $37^{\circ}$ or $4^{\circ}$. Triplicate sets of HEp-2 or Vero monolayers were inoculated with approximately 400 PFU (calculated from HSV-1 titer on HEp-2 cells) at either $37^{\circ}$ (A and B) or at $4^{\circ}$ (C and D). At selected time points beginning immediately after inoculation, one set of monolayers was washed and treated with PBS (open squares). PBS containing 500 $\mu \mathrm{g} / \mathrm{ml}$ heparin (open circles), or low pH citrate buffer (solid triangles) as described in the legend to Fig. 1 and then overlaid with either DME or 199 containing $0.5 \%$ methylcellulose. HEp-2 and Vero monolayers were fixed and plaques immunostained at $48-72 \mathrm{hr}$. The results are presented as the average number of PFU, from duplicate experiments, that survived each wash condition. Error bars indicate standard deviations. For some points, error bars are smaller than the plot symbol.

competitive effects of heparin on HEp-2 cells during the time required for attachment to HS.

Kinetics of HSV-1(F) entry show that progress from attachment through penetration differs between HEp-2 and Vero cells and correlates with plaquing efficiency (Table 1), rates of penetration (Fig. 1), and sensitivity to heparin during infection (Figs. 2 and 3 ). All three parameters of HSV-1 entry show cell-specific differences that likely are influenced by an initial PBS(R) attachment and a subsequent $H e p(R)$ stable attachment and seem to depend on the context of cell surface components characteristic of each cell line.

\section{Biochemical characterization of heparan sulfate on HEp-2 and Vero cells}

$\mathrm{HS}$ is one clearly identified cell surface component involved in HSV attachment that can vary on different cell lines (Shieh et al., 1992; WuDunn and Spear, 1989). To determine if variation in HS accounted for cell-specific kinetics and efficiency of entry, we biochemically characterized the amounts and average length of HS chains from total cellular HSPG of HEp-2 and Vero cells. The mature HS chains of HEp-2 cells averaged $105 \mathrm{kDa}$ in size and those of Vero averaged $58 \mathrm{kDa}$. The absolute amount of mature radiotabeled HS was about twofold greater on Vero cells (Table 3). These differences could influence virus interactions.

HSV-1 does not bind well to undersulfated HS (Lycke et al., 1991). Poor affinity of virus for less-sulfated HS could slow attachment and entry into a given cell line. To assess the influence of HS sulfation on HSV-1 attachment and entry, we determined the level of HS sulfation on HEp-2 and Vero cells. HS chain structure alternates between unmodified and heavily sulfated regions that are separated by blocks of varying sulfation. This pattern results from varying efficiencies of modifying enzymes and availability of substrates. We analyzed the amount of $N$-sulfation on HS fragments as a general index of total sulfation. Nitrous acid digests showed that HEp-2 HS contained $16 \%$ more $N$-sulfate groups than Vero cell HS (Table 3).

Free extracellular HSPG unique to each cell line might compete with cell surface HSPG for virus in a 
TABLE 2

TIME OF HSV-1 TRANSIT THROUGH STAGES OF ENTRY

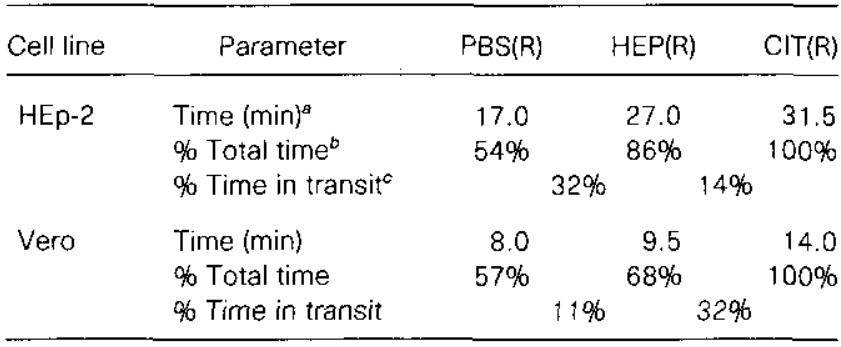

a Fime in minutes required for $50 \%$ of total PFU (200 PFU) to become resistant to PBS, heparin, or citrate wash at $37^{\circ}$ (Fig. 4).

${ }^{b}$ Percentage of time required for $200 \mathrm{PFU}$ to become resistant to the indicated wash condition, compared to the total time required for 200 PFU to achieve complete protection from extraceltular inactivation.

${ }^{c}$ Compared to total time before penetration, percentage of time 200 PFU spent in transit from resistance to one wash condition to resistance to the next wash condition.

manner similar to heparin competition. To address this possibility, HSPG was extracted and analyzed from medium in which HEp-2 or Vero cells had grown for $24 \mathrm{hr}$. HEp-2 cells shed approximately twice as much HSPG into the medium than did Vero cells (data not shown). However, extracellular HSPG did not obviously account for differences observed between the cells in infectivity, the rates of penetration, or heparin sensitivity. Extensive washing of cells before infection to remove extracellular HSPG or addition of medium from one monolayer of cultured cells to the other had little effect on the overall infectivity (data not shown).

Differences in total amounts (more on Vero), in length of chains (shorter on Vero), or in levels of sulfation (lower on Vero) might influence virus interactions with HS. One of many hypotheses is that HSV can more easily attach to and detach from Vero HS, while these events take more time with $\mathrm{HEp}-2 \mathrm{HS}$ that is longer and more highly sulfated. However, treating HEp-2 and Vero cells with sodium chlorate, which decreases HS sulfation, does not eliminate cell-specific heparin sensitivity (McClain et al., 1994). This suggests that other cell surface factors such as core proteins or the presence or type of some other non-heparan sulfate cell component(s) may influence cell-specific HSV attachment and entry. HS chains are attached to core proteins, which have not yet been examined and likely differ on HEp-2 and Vero cells.

\section{DISCUSSION}

Kinetics and efficiency of HSV-1 entry into two highly susceptible cell lines demonstrate the influence of temperature, viral and cell-specific components, and duration of incubation time on the cascade of virus-cell interactions during entry. We used kinetics of attach- ment through penetration to examine the influence of these variables on distinct stages of virus entry (Figs. 1 and 4; Table 2).

\section{Kinetics of penetration vary among wild-type strains}

Common HSV-1 wild-type laboratory strains vary in penetration rates and sensitivity to heparin (Figs. 1, 2, and 3 ). Because strain $F$ appears to be stable and intermediate in plaque phenotypes, rates of penetration, and pathogenesis, we performed entry studies with $\mathrm{HSV}-1(\mathrm{~F})$ as the standard wild-type virus. Recent studies with human immunodeficiency virus (Palca, 1992; Schuitemaker et al., 1992) and variations in HSV strains reported here (Figs. $1 \mathrm{C}$ and 3 ) and in the literature (Dix et al., 1983; Gordon et al., 1990; Shieh et al., 1992) suggest that the choice of virus strains should be carefully considered and that general conclusions should be confirmed with more than one viral strain or cell line, or specifically interpreted. This may be particularly important when comparing results of studies from different laboratories on viral entry, pathogenesis, and latency. Penetration rates are affected by a number of factors including natural and accumulated variations in viral components among common wild-type laboratory strains which may be numerous and are difficult to trace (Campadelli-Fiume et al., 1988; Lasky and Dowbenko, 1984; McGeoch et al., 1985; Watson et al., 1982).

\section{Cellular context is a major influence on kinetics and efficiency of entry}

Cell-specific differences for the same virus strain were found in rate of penetration, plaquing efficiency, heparin sensitivity, and infectivity (Figs. 1-3; Table 1). A mutant of 17 syn+ (17 hep syn) that was selected for heparin resistance (Goodman and Engel, 1991) also shows cell-specific heparin sensitivity. Infectivity in the presence of heparin differed more than 30-fold when the same inoculum was plated on Vero, rabbit skin, or HEp-2 cells (McClain and Fuller, unpublished). Clearly,

TABLE 3

Biochemical Analysis of Heparan Sulfate Proteoglycans

\begin{tabular}{lcc}
\hline & \multicolumn{2}{c}{ Cell line } \\
\cline { 2 - 3 } \multicolumn{1}{c}{ Parameter } & HEp-2 & Vero \\
\hline Total HSPG (cpm) & $4.46 \times 10^{4}$ & $9.40 \times 10^{4}$ \\
HSPG/total PG $(\%)$ & 24.0 & 25.0 \\
Chain size (kDa) & 105.0 & 58.0 \\
N-sulfation (\%) & 48.7 & 32.9 \\
\hline
\end{tabular}

a Total cpm of $\left[{ }^{3} \mathrm{H}\right]$ glucosamine, which labels all $\mathrm{HS}$ disaccharides regardless of sulfation, in HSPG pools isolated by ion-exchange chromatography of chondroitinase-treated cell extracts. 


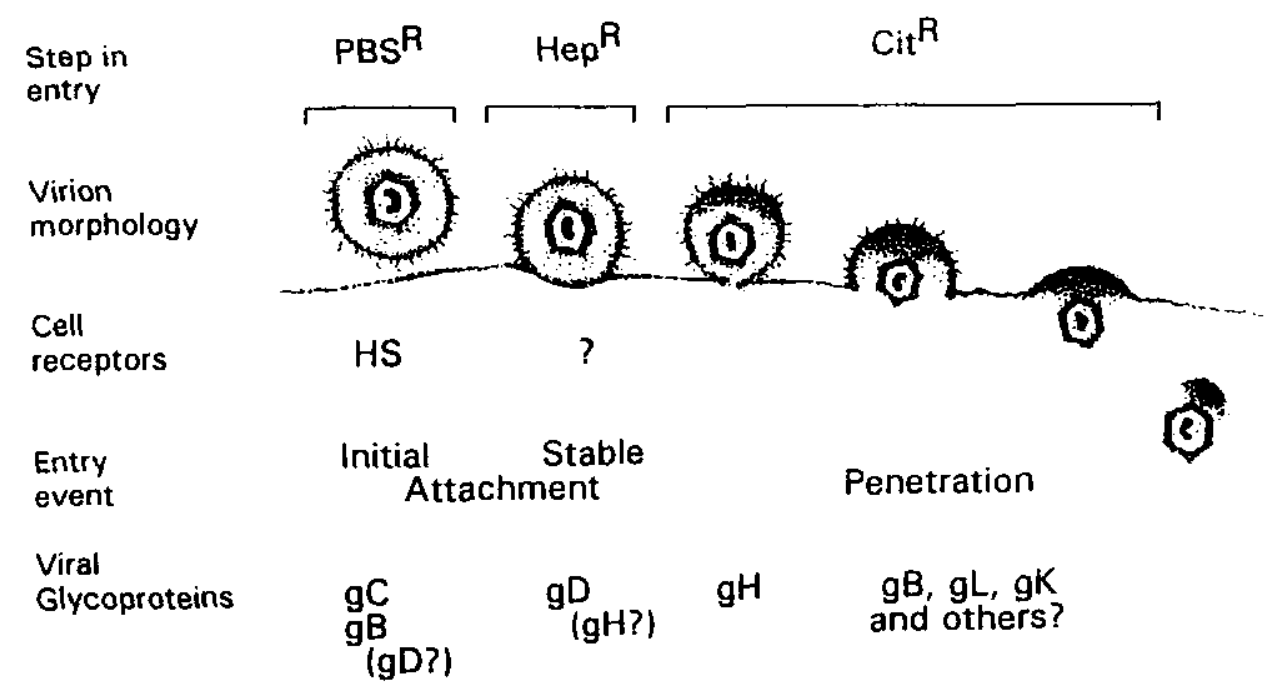

FIG. 5. Schematic of HSV-1 neutral pH entry of HSV-1. Schematic diagram (updated from Fuller and Lee, 1992) of multiple attachments during HSV-1 interactions with cells for infectious entry is shown. The proposed stages of entry are ordered by viral susceptibility to PBS, heparin, and citrate washes. The proposed receptors for each stage are HS for PBS(R) and an unidentified cell surface molecule for Hep(R). The diagram is based on specific information for HSV-1 in this report and available in the field. Similar multiple attachments during entry were proposed for PRV (Karger and Mettenleiter, 1993) and HCMV (Compton et al., 1993).

cellular context, whether due to HS or other receptors, influences the distinct phases of attachment of wildtype virus to highly susceptible cells (Fig. 4). Different types of attachment aiso have been postulated to explain observations in systems where the viral glycoproteins or cell surfaces are known to be altered (Gruenheid et al., 1993; Herold et al., 1991; Sears et al., 1991; Shieh et al., 1992). These results indicate influence on entry of virus interaction with specific cell components that vary on different cells.

\section{Kinetics of entry agree with multiple attachments in HSV entry}

Kinetics of HSV-1 attachment and penetration provide strong evidence for a cascade of multiple viruscell interactions in HSV entry (Fuller and Lee, 1992) (Fig. 5). HSV-1(F) enters into both HEp-2 and Vero cell lines in at least three distinct phases of PBS(R) attachment, Hep(R) attachment, and Cit(R) penetration (Fig. 4). These phases are consistent with HSV-1 entry by (1) initial attachment to cell surface HS, heparin-resistant or (2) stable attachment to HS or another component and (3) fusion initiation and expansion that is triggered by stable attachment and culminates in virus penetration to be protected from extracellular inactivation (Fuller and Lee, 1992; Fig. 5). Duration of each stage of HSV-1(F) entry into HEp-2 and Vero cells is influenced by the cell-specific context of virus receptor(s) (Fig. 4 and Table 2).

Initial attachment to $\mathrm{HS}$, likely by $\mathrm{gB}$ and $\mathrm{gC}$ (Herold et al., 1991; Kuhn et al., 1990), allows HSV-1 to remain associated with the cell in a manner resistant to mechanica! PBS washing (Fuller and Lee, 1992). Stable attachment follows, likely involves gD (Fuller and Lee,
1992; Lee and Fuller, 1993), is resistant to heparin wash, and is proposed to be a prerequisite for virus fusion with the plasma membrane (Fuller et al., 1994). Stably attached virus appeared by electron microscopy to be closely associated with the cell membrane in a manner that could involve binding of multiple virion components to cell components. These could be multivalent HS-virus interactions or interactions of $\mathrm{gD}$, at least, with a non-HS receptor (Lee and Fuller, 1993; Johnson and Ligas, 1988). Either, or both, could result in resistance to heparin wash (Fuller and Lee, 1992; Fig. 4). We cannot yet distinguish between these since both would be resistant to heparin wash and still sensitive to extracellular inactivation. Kinetics of HSV-1(F) entry define PBS(R)-Hep(S) and PBS(R)-Hep(R) phases of virus entry that likely correspond to initial and stable attachment (Figs. 4 and 5).

Cell-specific effects of heparin (Fig. 3) and kinetics of attachment (Fig. 4) suggest that initial attachment to HS likely influences transitions to, and beyond, stable attachment. A particular valency of attachment, or avidity for HS, during virus binding may be required to alter a virus particle to allow efficient stable attachment and triggering of virion-cell fusion. Alternatively, HS binding may only enhance the probability that virus binds to the non-HS receptor. Subsequent to the two discernible phases of $\mathrm{PBS}(\mathrm{R})$ and $\mathrm{Hep}(\mathrm{R})$ attachment, HSV penetration is completed by fusion of the virion envelope with the cell membrane and release of the nucleocapsid (Fig. 5). Events occurring during, or as a result of, stable virus attachment are proposed to mediate changes in glycoprotein conformation and trigger virus fusion (Fuller and Lee, 1992; Marsh and Helenius, 1989; White, 1990). Similar conformational changes 
have been proposed during entry of several enveloped viruses (Flynn et al., 1990; Sattentau and Moore, 1991; Sturman et al., 1990).

Transition of virus from $\mathrm{Hep}(\mathrm{R})$ stable attachment to $\mathrm{Cit}(\mathrm{R})$ penetration is likely a highly vulnerable point of infection since the stable structure of extracellular virion morphology must be irreversibly altered to allow disassembly. HSV-1(F) proceeds quickly through this transition on HEp-2 cells that originate from the native host of HSV. The critical penetration step in virus entry may be optimized for interactions with cell surface components. Kinetics of infectious entry into two highly susceptible cultured cells prompts speculation that stable attachment of HSV-1 to trigger fusion may be the rate-limiting step that is slow and deliberate on some cells, i.e., human cells, to prepare for efficient and rapid disassembly during virion-cell fusion.

\section{Multiple cell receptors indicated for HSV}

Analysis of HSV-1 entry as a cooperative cascade of events (this work; Fuller and Lee, 1992; Lee and Fuller, 1993) reveals involvement of multiple cellular components. Both HS and a second non-HS receptor(s) are involved in HSV-1 entry and the distinct steps of attachment (Campadelli-Fiume et al., 1988; Fuller and Lee, 1992; Gruenheid et al., 1993; Johnson et al., 1990; Johnson and Ligas, 1988; Johnson and Spear, 1989; Lee and Fuller, 1993; Sears et al., 1991; Subramanian et al., 1994). Saturation of cells to prevent in fection did not saturate virus binding to HS (Lee and Fuller, 1993) and demonstrated requirement for a limited non-HS cell surface component. We also have found that cells which are poorly susceptible to HSV infection contain functional $\mathrm{HS}$, but seem to lack a functional non-HS receptor (Subramanian et al., 1993). For these poorly susceptible cells, susceptibility to HSV-1 infection can be increased by transfection of virus DNA or polyethylene glycol-mediated virus fusion, or can be genetically transferred by transfection with genomic DNA from susceptible cells (Subramanian et al., 1994). Presence or quantity of a stable nonHS attachment receptor (Fig. 5), such as the receptor for gD binding, or other receptors, is consistent with all these findings and could be a major determinant of the cell-specific differences in HSV-1 attachment and penetration into HEp-2 and Vero cells.

Experiments are in progress to examine the fine structure of $\mathrm{HS}$ and to identify the cell surface factor that may account for some of the cell-specific virus interactions reported here, and for cell susceptibility and host range of HSV-1. Given its ubiquitous distribution, HS does not seem an obvious determinant of HSV-1 tropism. Although HS may contribute to observed cell-specific differences in initial attachment (Fig. 4), its roles in stages subsequent to initial attachment (Fig. 5) are unclear. Attachment to HS may concentrate virions on the cell surface to allow easier ac- cess or frequency of contact with a second receptor or may be required for changes in virus structure that facilitate penetration.

\section{Multiple attachments in neutral $\mathrm{pH}$ virus entry}

Besides HSV-1 (this study; Lee and Fuller, 1993; Sears et al., 1991), two other herpesviruses, PRV (Karger and Mettenleiter, 1993) and HCMV (Compton et al., 1993), recently have been shown to enter cells by at least two types of attachment. These viruses can enter cells by fusion at neutral $\mathrm{pH}$ with the plasma membrane (Fuller and Spear, 1987; Wittels and Spear, 1990; Compton et al., 1992; Lee and Fuller, 1994). Interestingly, for all three viruses, HS and another nonHS component are implicated. These findings suggest that multiple sequential or simultaneous attachments are important in the mechanism of efficient entry of some enveloped viruses by fusion with plasma membrane. Multiple attachments would allow controlled attachment and penetration of a virus particle to a cell that has the necessary components. Moreover, this mechanism would provide flexibility in entry into different cell types, such as those encountered in the lytic and latent phases of infection by these herpesviruses in their natural hosts. This possible mechanism of entry by herpesviruses is explored elsewhere (Fuller and Mettenleiter, 1994) and seems to be consistent with neutral $\mathrm{pH}$ entry of a number of enveloped viruses.

\section{ACKNOWLEDGMENTS}

We thank $V$. Hascall and M. Yanagishita for invaluable guidance in HSPG characterization. We also thank Ning McLaren and Melody Neely for assistance with cell culture, Jeff Engel and Priscilla Schaffer for viruses, and Ann Haywood and members of our laboratory for helpful discussions. D.S.M. is a trainee supported by T-32-A107360 from the NIAID. The work was supported by an American Cancer Society Institutional Research Award IN-40-30 to the University of Michigan and Grant Al28378 from NIH to A.O.F.

\section{REFERENCES}

CAI, W., GU, B., and PERSON, S. (1988). Role of glycoprotein B of herpes simplex virus type 1 in viral entry and cell fusion. J. Virol. 62 , 2596-2604.

Campadelli-Fiume, G., Arsenakis, M., Farabegoli, F., and Rolzman, B. (1988). Entry of herpes simplex virus 1 in BJ cells that constitutively express viral glycoprotein $D$ is by endocytosis and results in degradation of the virus. J. Virol. 62, 159-167.

Campadelli-Fiume, G., Ql, S., Avitable, E., Foa-Tomasi, L., BrandiMARTI, R., and RoIZMAN, B. (1990). Glycoprotein D of herpes simplex virus encodes a domain which precludes penetration of cells expressing the glycoprotein by superinfecting herpes simplex virus. J. Virol. 64, 6070-6079.

Compton, T., Nepomuceno, R, and Nowlin, D. M. (1992). Human cytomegalovirus penetrates host cells by $\mathrm{pH}$-independent fusion at the cell surface. Virology 191, 387-395.

COMPTON, T., NOWLIN, D. M., and COOPER, N. R. (1993). Initiation of human cytomegalovirus infection requires initial interaction with cell surface heparan sulfate. Virology 193, 834-841. 
Desal, P. J., Schaffer, P. A., and Minson, A. C. (1988). Excretion of non-infectious virus particles lacking glycoprotein $\mathrm{H}$ by a temperature-sensitive mutant of herpes simplex virus type 1: Evidence that $\mathrm{gH}$ is essential tor virion intectivity. J. Gen. Virol. 69, 1147-1156.

DIX, R. D., MCKENDALL, R. R., and BARRINGER, R. (1983). Comparative neurovirulence of herpes simplex virus type 1 strains after peripheral or intracerebral inoculation of BALB/c mice. Infect. Immun. 40 , 103-112.

FLyNn, D. C., MEYER, W. J., MACKENZIE, J. M., JR., and JOHNSTON, R. E. (1990). A conformational change in Sindbis virus glycoprotein $E 1$ and $E 2$ is detected at the plasma membrane as a consequence of early virus-cell interaction. J. Virol. 64, 3643-3653.

Forrester, A., FARrell, H., WILKInson, G., Kaye, J., DaVIS-PoYnter, N., and MINSON. T. (1992). Construction and properties of a mutant herpes simplex virus type 1 with glycoprotein $\mathrm{H}$ coding sequences deleted. J. Virol. 66, 341-348.

Fuller, A. O., and LEE, W.-C. (1992). Herpes simplex virus type 1 entry through a cascade of virus-cell interactions requires different roles of $\mathrm{gD}$ and $\mathrm{gH}$ in penetration. J. Virol. 66, 5002-5012.

Fuller, A. O., and Mettenleiter, T. C. (1994). "Multiple attachments of herpesviruses during neutral pH entry." In preparation.

Fuller, A. O., Novotney, M., MCLaren, N., Johnson, R., and SPEar, P. G. (1994). "Expression of herpes simplex virus $g D$ enhances PEG mediated cell fusion but is not sufficient to mediate cell fusion." Submitted for publication.

Fuller, A. O., Santos, R., and Spear, P. G. (1989). Potent neutralizing antibodies to $\mathrm{gH}$ of herpes simplex virus do not block attachment but prevent penetration of virus. J. Virol. 63, 3535-3543.

Fuller, A. O., and SPEAR, P. G. (1985). Specificities of monoclonal and polyclonal antibodies that inhibit adsorption of herpes simplex virus to cells and lack of inhibition by potent neutralizing antibodies. J. Virol. 55, 475-482.

FUlLer, A. O., and SPEAR, P. G. (1987). Anti-glycoprotein D antibodies that permit adsorption but block infection by herpes simplex virus 1 prevent virion cell fusion at the cell surface. Proc. Natl. Acad. Sci. USA 84, 5454-5458.

Goodman, J. L., and EngeL, J. P. (1991). Altered pathogenesis in herpes simplex virus type 1 infection due to a syncytial mutation mapping to the carboxyl terminus of glycoprotein B. J. Virol. 65 , $1770-1778$.

Gordon, Y. J., McKNiGht, L. C., Ostrove, J. M., Romanowski, E., and Araullo-Cruz, T. (1990). Host species and strain differences affect the ability of an HSV-1 ICPO deletion mutant to establish latency and spontaneously reactivate in vivo. Virology 178, 469477

Gruenheid, S., Gatzke, L., Meadows, H., and Tufaro, F. (1993). Herpes simplex virus infection and propagation in a mouse $L$ cell mutant lacking heparan sulfate proteoglycans. J. Virol. 67, 93100.

Herold, B. C., Wudunn, D., Soltys, N., and Spear, P. G. (1991). Glycoprotein $C$ of herpes simplex virus type 1 plays a principal role in the adsorption of virus to cells and in infectivity. /. Virol. 65 , 1090-1098.

Highlander, S. L., Cai, W., Person, S., Levine, M., and Glorioso, J. C. (†988). Monoclonal antibodies define a domain on herpes simplex virus glycoprotein $B$ involved in virus penetration. J. Virol. 62, 1881-1888.

Huang, A. S., Palma, E. L., Hewlett, N., and Roizman, B. (1974). Pseudotype formation between enveloped RNA and DNA viruses. Nature (London) 252, 743-745.

HuAng, A. S., and Wagner, R. R. (1964). Penetration of herpes simplex virus into human epidermoid celis. Proc. Soc. Exp. Biol. Med. $116,863-869$.

JOHNSON, D. C., BURKE, R. L., and GREgory, T. (1990). Soluble forms of herpes simplex virus glycoprotein $D$ bind to a limited number of cell surface receptors and inhibit virus entry into cells. J. Virol. 64, 2569-2576.
JOHNSON, D. C., and LIGAS, M. W. (1988). Herpes simplex viruses lacking glycoprotein $D$ are unable to inhibit virus penetration: Quantitative evidence for virus specific cell surface receptors. J. Virol. 62, 4605-4612.

JOHNSON, R. M., and SPEAR, P. G. (1989). Herpes simplex virus glycoprotein $D$ mediates interference with herpes simplex virus infection. J. Virol. 63, 819-827.

KARger, A., and MettenLeiter, T. C. (1993). Glycoproteins gll and gp50 play dominant roles in the biphasic attachment of pseudorabies virus. Virology 194, 654-663.

KIELLÉN, L., and LINDAHL, U. \{1991\}. Proteoglycans: Structures and interactions. Annu. Rev. Biochem. 60, 443-475.

Kuhn, J. E., Kramer, M. D., WILlenbacher, W. Wieland, U., LORENTZEN, E. U., and BRAUN, R. W. (1990). Identification of herpes simplex virus type 1 glycoproteins interacting with the cell surface. $)$. Virol. 64, 2491-2497.

LASKY, L. A., and DOWBENKO, D. J. (1984). DNA sequence analysis of the type-common glycoprotein-D genes of herpes simplex virus types 1 and 2. DNA 3, 23-29.

LEE, W.-C., and FULLER, A. O. (†993). Herpes simplex virus and pseudorabies virus bind to a common cell surface receptor on Vero cells that is not heparan sulfate. J. Virol. 67, 5088-5097.

LEE, W.-C., and FuLLER, A. O. (1994). "Pseudorabies virus entry occurs by direct fusion at neutral $\mathrm{pH}$." Submitted for publication.

LIGAS, M. W., and JOHNSON, D. C. (1988). A herpes simplex virus mutant in which glycoprotein $D$ sequences are replaced by betagalactosidase sequences binds to but is unable to penetrate into cells. J. Virol. 62, 1486-1494.

LINDAHL, U., and KJELLEN, L. (1991). Heparin or heparan sulfateWhat is the difference? Thromb. Haemostasis 66, 44-48.

LYCKE, E., JOHANSSON, M., SVENNERHOLM, B., and LINDAHL, U. (1991). Binding of herpes simplex virus to cellular heparan sulphate, an initial step in the adsorption process. J. Gen. Virol. 72, 1131-1137.

MARSH, M., and HELENIUS, A. (1989). Virus entry into animal cells. Adv. Virus Res. 36, 107-151.

McClain, D. S., Yanagishita, M., Hascall, V., and Fuller, A. O. (1994). "Requirements for heparan sulfate and other receptors in entry of herpes simplex virus." Submitted for publication.

MCGeoch, D. J., Dolan, A., DONald, S., and Rixon, F. J. (1985). Sequence determination and genetic content of the short unique region in the genome of herpes simplex virus type 1. J. Mol. Biol. 181, 1-13.

METtEnLeiter, T. C. (1989). Glycoprotein gll! deletion mutants of pseudorabies virus are impaired in entry. Virol. 171, 623-625.

NAHMIAS, A. J., and KIBRICK, S. (1964). Inhibitory effect of heparin on herpes simplex virus. I. Bacteriol. 87, 1060-1066.

PALCA, J. (1992). Errant HIV strain renders test virus stock useless. Science 256, $13487-13488$.

SATTENTAU, Q. J., and MOORE, J. P. (1991). Conformational changes induced in the human immunodeficiency virus envelope glycoprotein by soluble CD4 binding. J. Exp. Med. 174, 407-415.

Schuitemaker, H., Kootstra, N. A., Dercksen, M. W., DeGoede, R. E. Y., VanSteenwuk, R. P., Lange, J. M. A., Eeftink ScatienKerK, J. K. M. MiedemA, F., and TERSMETTE, M. (1992). Biological phenotype of human immunodeficiency virus type- 1 clones at different stages of infection: Progression of disease is associated with a shift from monocytotropic to T-cell-tropic virus populations. J. Virol. 66, 1354-1360.

Sears, A. E., MCGwire, M. S., and RoIzMan, B. (1991). Infection of polarized MDCK cells with herpes simplex virus 1: Two asymmetrically distributed cell receptors interact with different viral proteins. Proc. Natl. Acad. Sci. USA 88, 5087-5091.

SHIEH, M.-T., WuDunN, D., MONTGOMERY, R. I., EsKO, J., and SPEAR, P. G. (1992). Cell surface receptors for herpes simplex virus are heparan sulfate proteoglycans. J. Cell Biol. 116, 1273-1281.

ShIVELy, J. E., and CONRAD, H. E. (1976). Formation of anhydrous sugars on the chemical depolymerization of heparin. Biochemistry $15,3932-3942$. 
SPEAR, P. G. (1993). Entry of alphaherpesviruses into cells. Semin. Virol. 4, 167-180.

Sturman, L. S., Ricard, C. S., and Holmes, K. V. (1990). Conformational change of the coronavirus peplomer glycoprotein at $\mathrm{pH} 8.0$ and $37^{\circ} \mathrm{C}$ correlates with virus aggregation and virus induced cell fusion. J. Virol. 64, 3042-3050.

Subramanian, G., Perez, A., McClain, D. S., and Fuller, A. O. (1994). "Transfer of susceptibility to herpes simplex virus infection to swine testis cells that are defective in entry." /. Virol. In Press.

WATSON, R. J., WEIS, R. J., SALSTROM, J. S., and Enouist, L. W. (1982). Herpes simplex virus type 1 glycoprotein D gene: Nucleotide sequence and expression in Escherichia coli. Science 218, 381384.

WHITE, J. M. (1990). Viral and cellular fusion proteins. Annu. Rev. Physiol. 52, 675-697.
Wight, T. N., HeINEGÅRD, D. K., and Hascall, V. C. (1991). Proteoglycans: Structure and function. In "Cell Biology of Extracellular Matrix" (E. G. Hay, Ed.), 2nd ed., pp. 45-78. Plenum, New York.

WITtEls, M., and SPEAR, P. G. (1990). Penetration of cells by herpes simplex virus does not require a low $\mathrm{pH}$-dependent endocytic pathway. Virus Res. 18, 271-290.

WUDUNN, D. W., and SPEAR, P. G. (1989). Initial interaction of herpes simplex virus with cells is binding to heparan sulfate. I. Virol. 63 , 52-58.

YANAGISHITA, M. (1992). Metabolic labeling of glycosylphosphatidylinositol anchor of heparan sulfate proteoglycans in rat ovarian granulosa cells. J. Biol. Chem. 267, 9499-9504.

YANAGISHITA, M., MIDURA, and HASCALL, V. C. (1987). Proteoglycans: Isolation and purification from tissue cultures. Methods Enzymol. $138,279-289$. 